\title{
Electrical and Catalytic Properties of some Oxides with the Fluorite or Pyrochlore Structure
}

$\mathrm{CO}$ Oxidation on some Compounds derived from $\mathrm{Gd}_{2} \mathrm{Zr}_{2} \mathrm{O}_{7}$

\author{
Stefan J. Korf, Harry J. A. Koopmans, Bernard C. Lippens Jr, \\ Anthonie J. Burggraaf and Paul J. Gellings*
}

Laboratory for Inorganic Chemistry, Materials Science and Catalysis, Twente

University of Technology, P.O. Box 217, 7500 AE Enschede, The Netherlands

\begin{abstract}
The catalytic properties of some mixed zirconates with the pyrochlore or fluorite structure have been investigated using $\mathrm{CO}$ oxidation as the test reaction. The presence of terbium ions, leading to mixed conductivity, and the extent of pyrochlore ordering affect the kinetic behaviour and the catalytic activity of the investigated materials. Bismuth-containing compounds show an increased rate of reoxidation.
\end{abstract}

In some previous papers ${ }^{1,2}$ the electrical and catalytic behaviour of some oxides with the fluorite or pyrochlore structure was reported. These were devoted to some pyrochlore titanates and cerium-substituted neodymium zirconates. It was shown that the presence of ions with a variable valence state and the extent of pyrochlore ordering affect the kinetic behaviour and the activity of the investigated materials.

In this paper the study of some substituted compounds derived from $\mathrm{Gd}_{2} \mathrm{Zr}_{2} \mathrm{O}_{7}$ or $\mathrm{Tb}_{2} \mathrm{Zr}_{2} \mathrm{O}_{7}$ is presented. [Note, for the compounds $\left(\mathrm{Tb}_{x} \mathrm{Gd}_{1-x}\right)_{2} \mathrm{Zr}_{2} \mathrm{O}_{7}$ the shorthand notation TGZ $(100 x)$ is used, thus TGZ40 is a compound in which $x=0.4$.]

The electrical properties of these compounds have been studied by van Dijk et al. ${ }^{3,4}$ The transport number measurements show that TGZ0 is a purely ionic conductor, while with increasing terbium content an increasing electronic conduction is observed. The ionic transport number decreases with decreasing temperature, which is mainly caused by the observed increase in charge carriers for electronic conduction $\left(\mathrm{Tb}^{4+}\right)$ with decreasing temperature, and partly by the differences in activation energy for ionic and electronic conduction. ${ }^{5}$ All measurements have shown that in these compounds there is p-type electronic conduction. Arrhenius plots for the total conduction are non-linear, showing that, in agreement with the transport number measurements, at least two conduction mechanisms with different activation energies play a role.

Van Dijk ${ }^{3}$ has also shown that increasing pyrochlore ordering is accompanied by a decrease of the activation energy for ionic conduction. This may increase the catalytic oxidation and reduction activity when these processes involve the participation of lattice oxygen ions, because the lower activation energy for ionic conduction might be connected with the ease of oxygen exchange with the gas phase.

\section{Synthesis of Compounds}

\section{Experimental}

The compounds were synthesized using the so-called 'citrate method', for a detailed description of which we refer to the literature. ${ }^{6}$ In principle this method consists in making a solution of the nitrates of the different metals in the desired proportion, complexing with an excess of citric acid, neutralizing with ammonia, followed by evaporation and pyrolysis of the resulting viscous solution. 
Table 1. Surface areas of catalysts calcined at $1073 \mathrm{~K}$

\begin{tabular}{lc}
\hline \multicolumn{1}{c}{ catalyst } & $S_{\mathrm{BET}} / \mathrm{m}^{2} \mathrm{~g}^{-1}$ \\
\hline $\mathrm{Gd}_{2} \mathrm{Zr}_{2} \mathrm{O}_{7}$ & $9.8 \pm 0.8$ \\
$\left(\mathrm{~Tb}_{0.2} \mathrm{Gd}_{0.8}\right)_{2} \mathrm{Zr}_{2} \mathrm{O}_{7}$ & $11.5 \pm 0.6$ \\
$\left(\mathrm{~Tb}_{0.4} \mathrm{Gd}_{0.6}\right)_{2} \mathrm{Zr}_{2} \mathrm{O}_{7}$ & $14.0 \pm 1.0$ \\
$\left(\mathrm{~Tb}_{0.6} \mathrm{Gd}_{0.4}\right)_{2} \mathrm{Zr}_{2} \mathrm{O}_{7}$ & $15.8 \pm 0.6$ \\
$\mathrm{~Tb}_{2} \mathrm{Zr}_{2} \mathrm{O}_{7}$ & $12.5 \pm 0.7$ \\
$\left(\mathrm{~Tb}_{0.95} \mathrm{Bi}_{0.05}\right)_{2} \mathrm{Zr}_{2} \mathrm{O}_{7}$ & $22.8 \pm 0.8$ \\
$\left(\mathrm{~Tb}_{0.9} \mathrm{Bi}_{0.1}\right)_{2} \mathrm{Zr}_{2} \mathrm{O}_{7}$ & $20.4 \pm 0.9$ \\
\hline
\end{tabular}

Table 2. Surface areas of heat-treated catalysts

\begin{tabular}{cccr}
\hline & \multicolumn{3}{c}{$S_{\text {BET }} / \mathrm{m}^{2} \mathrm{~g}^{-1}$} \\
\cline { 2 - 4 }$T / \mathrm{K} \mathrm{Gd}_{2} \mathrm{Zr}_{2} \mathrm{O}_{7}$ & $\left(\mathrm{~Tb}_{0.4} \mathrm{Gd}_{0.6}\right)_{2^{-}}$ & $\mathrm{Zb}_{2} \mathrm{Zr}_{2} \mathrm{O}_{7}$ \\
\hline 1073 & $9.8 \pm 0.8$ & $14.0 \pm 1.0$ & $12.5 \pm 0.7$ \\
1423 & $3.6 \pm 0.2$ & $3.3 \pm 0.4$ & $4.1 \pm 0.3$ \\
1523 & $3.0 \pm 0.4$ & $2.3 \pm 0.4$ & $3.6 \pm 0.3$ \\
1623 & $1.3 \pm 0.6$ & $1.4 \pm 0.6$ & $2.4 \pm 0.4$ \\
\hline
\end{tabular}

All oxides were calcined at $1073 \mathrm{~K}$ in air to remove carbon formed by incomplete combustion of the citrate. In order to obtain compounds with different amounts of pyrochlore ordering, three heat treatments were carried out at 1423,1523 and $1623 \mathrm{~K}$ for $24 \mathrm{~h}$ on isostatically pressed samples of the powders.

\section{Analysis and Characterization}

The composition of the oxides was checked by X-ray fluorescence analysis and was found to deviate $<c a .1 \%$ from the desired composition in all cases. Only the Bi-containing compounds showed some bismuth deficiency.

X-Ray powder diffraction was carried out on a Philips PW1050 diffractometer using $\mathrm{Cu} K \alpha$ radiation.

Surface areas were determined by the B.E.T. method using Ar adsorption.

\section{Catalytic Measurements}

Catalytic measurements were performed in a tubular microreactor with a fixed catalyst bed, consisting of $300 \mathrm{mg}$ of catalyst grains of $0.3-0.6 \mathrm{~mm}$ diameter, mixed with the same amount of quartz grains of the same diameter to avoid the formation of hot spots.

The gas flow was $c a .1 \mathrm{~cm}^{3} \mathrm{~s}^{-1}$ with a composition of $4-10 \% \mathrm{CO}, 4-12 \% \mathrm{O}_{2}$, balance $\mathrm{N}_{2}$, always with an excess of $\mathrm{O}_{2}$. The $\mathrm{CO}$ conversion was determined by titration of the $\mathrm{CO}_{2}$ formed and the conversions were between 0.5 and $40 \%(T=600-750 \mathrm{~K})$. 
Table 3. CO oxidation on calcined catalysts $\left(T_{\text {calcd }}=1073 \mathrm{~K}\right)$

\begin{tabular}{llllcc}
\hline \multicolumn{1}{c}{ catalyst } & $\begin{array}{c}n \\
( \pm 0.1)\end{array}$ & $\begin{array}{c}m \\
( \pm 0.1)\end{array}$ & $\begin{array}{c}\ln \left(k_{\mathbf{0}}\right) \\
( \pm 0.6)\end{array}$ & $\begin{array}{c}E_{\mathrm{A}}( \pm 4) \\
/ \mathrm{kJ} \mathrm{mol}^{-1}\end{array}$ & $\begin{array}{c}r_{223}{ }^{2} \\
\mathrm{~mol} \mathrm{~m}^{-2} \mathrm{~s}^{-1}\end{array}$ \\
\hline TGZ0 & 0.6 & 0.25 & 16.3 & 113 & 5.6 \\
TGZ20 & 0.5 & 0.4 & 12.5 & 90 & 3.0 \\
TGZ40 & 0.45 & 0.3 & 11.5 & 90 & 8.7 \\
TGZ60 & 0.35 & 0.35 & 11.5 & 91 & 17 \\
TGZ100 & 0.25 & 0.4 & 11.6 & 92 & 32 \\
$\left(\mathrm{~Tb}_{\mathbf{0 . 9 5}} \mathrm{Bi}_{\mathbf{0 . 0 5}}\right)_{2} \mathrm{Zr}_{2} \mathrm{O}_{7}$ & 0.4 & 0.2 & 10.2 & 86 & 36 \\
$\left(\mathrm{~Tb}_{\mathbf{0 . 9}} \mathrm{Bi}_{\mathbf{0 . 1}}\right)_{2} \mathrm{Zr}_{\mathbf{2}} \mathrm{O}_{7}$ & 0.5 & 0.05 & 9.6 & 82 & 70 \\
\hline
\end{tabular}

${ }^{a}$ Gas composition: $2.5 \% \mathrm{CO}, 6 \% \mathrm{O}_{2}$.

Table 4. CO oxidation on heat-treated catalysts

\begin{tabular}{llccccc}
\hline \multicolumn{2}{c}{ catalyst } & $\begin{array}{c}n \\
( \pm 0.1)\end{array}$ & $\begin{array}{c}m \\
( \pm 0.1)\end{array}$ & $\begin{array}{c}\ln \left(k_{0}\right) \\
( \pm 0.6)\end{array}$ & $\begin{array}{c}E_{\mathrm{A}}( \pm 4) \\
/ \mathrm{kJ} \mathrm{mol}^{-1}\end{array}$ & $\begin{array}{c}r_{723}{ }^{a} \\
\mathrm{~mol} \mathrm{~m}^{-2} \mathrm{~s}^{-1}\end{array}$ \\
\hline TGZ0 & 1073 & 0.6 & 0.25 & 16.3 & 113 & 5.6 \\
TGZ0 & 1423 & -0.05 & 0.9 & 17.0 & 109 & 39 \\
TGZ0 & 1523 & -0.25 & 0.2 & 8.9 & 92 & 40000 \\
TGZ0 & 1623 & 0.2 & 0.1 & 8.0 & 79 & 920 \\
TGZ40 & 1073 & 0.45 & 0.3 & 11.5 & 90 & 8.7 \\
TGZ40 & 1423 & 0.35 & 0.25 & 11.1 & 86 & 97 \\
TGZ40 & 1523 & 0.25 & 0.3 & 9.7 & 83 & 81 \\
TGZ40 1623 & 0.75 & 0.35 & 12.7 & 83 & 0.66 \\
TGZ100 1073 & 0.25 & 0.4 & 11.6 & 92 & 32 \\
TGZ100 1423 & 0.35 & -0.05 & 7.3 & 79 & 400 \\
TGZ100 1523 & 0.15 & 0.25 & 7.3 & 82 & 74 \\
TGZ100 1623 & 0.05 & 0.4 & 6.2 & 75 & 44 \\
\hline
\end{tabular}

${ }^{a}$ Gas composition: $2.5 \% \mathrm{CO}, 6 \% \mathrm{O}_{2}$.

\section{Results}

The surface areas of catalysts are given in tables 1 and 2 .

The catalytic behaviour of the different compounds is characterized using the kinetic equation:

$$
r=k_{0} \exp \left(-E_{\mathrm{A}} / R T\right)[\mathrm{CO}]^{n}\left[\mathrm{O}_{2}\right]^{m}
$$

where $r$ is the specific reaction rate $\left(\mathrm{mol} \mathrm{m}^{-2} \mathrm{~s}^{-1}\right), k_{0}$ is the pre-exponential constant, $E_{\mathrm{A}}$ is the activation energy $\left(\mathrm{kJ} \mathrm{mol}^{-1}\right)$ and $n$ and $m$ are the reaction orders in $\mathrm{CO}$ and $\mathrm{O}_{2}$, respectively. $\mathrm{Yao}^{7}$ uses a similar equation to describe the kinetics of several catalytic oxidation reactions for which the exact mechanism is still unknown.

As remarked in a previous paper ${ }^{2}$ the reaction orders vary appreciably from one material to another, making it impossible to characterize the catalysts with $k_{0}$ and $E_{\mathrm{A}}$ only, as is usually done. Therefore the specific reaction rates are compared at an arbitrarily chosen temperature and gas composition, namely $723 \mathrm{~K}, 2.5 \% \mathrm{CO}$ and $6 \%$ $\mathrm{O}_{2}$.

In table 3 the results obtained in this way for the calcined catalysts are given. The orders $n$ and $m$, the pre-exponential factor $k_{0}$ and the activation energy $E_{\mathrm{A}}$ have been calculated 
from the experimental data using a computer program based on the Nelder-Mead optimization method. In table 4 the results obtained on the heat-treated catalysts are collected.

\section{Discussion}

\section{Introduction}

In most studies concerning the oxidation of $\mathrm{CO}$ on oxidic catalysts reduction of the surface by formation of $\mathrm{CO}^{+}$is supposed to be the first step of the reaction mechanism. ${ }^{8,9}$ The $\mathrm{CO}^{+}$ions then react with lattice oxygen ions to form adsorbed carboxylate $\left(\mathrm{CO}_{2}^{-}\right)$ ions. ${ }^{8,10,11} \mathrm{After}$ the formation of gaseous $\mathrm{CO}_{2}$ the surface is reoxidized by oxygen from the gas phase. The following mechanism can be used in the description of the oxidation of $\mathrm{CO}$ on the catalysts studied here: ${ }^{2}$

$$
\begin{aligned}
& \mathrm{CO}_{\mathrm{g}}+\mathrm{h}^{\cdot} \rightleftharpoons \mathrm{CO}_{\mathrm{ads}}^{+} \\
& \mathrm{CO}_{\mathrm{ads}}^{+}+\mathrm{O}_{0}^{x} \rightleftharpoons \mathrm{CO}_{2, \mathrm{ads}}^{-}+\mathrm{V}_{0}^{*} \\
& \mathrm{CO}_{2, \text { ads }}^{-}+\mathrm{h}^{\cdot} \rightleftharpoons \mathrm{CO}_{2, \mathrm{~g}} \\
& \text { or } \mathrm{CO}_{2, \text { ads }}^{-}+\mathrm{O}_{0}^{x}+\mathrm{h}^{\cdot} \rightleftharpoons \mathrm{CO}_{3, \text { ads }}^{2-}+\mathrm{V}_{0} \cdot \\
& \mathrm{CO}_{3, \text { ads }}^{2-}+\mathrm{V}_{0}^{\prime} \rightleftharpoons \mathrm{CO}_{2, \mathrm{~g}}+\mathrm{O}_{0}^{x} \\
& \mathrm{O}_{2, \mathrm{~g}} \rightleftharpoons \mathrm{O}_{2, \text { ads }}^{-}+\mathrm{h}^{\text {. }} \\
& \mathrm{O}_{2, \text { ads }}^{-} \rightleftharpoons \mathrm{O}_{2, \text { ads }}^{2-}+\mathrm{h}^{.} \\
& \mathrm{O}_{2, \text { ads }}^{2-} \rightleftharpoons 2 \mathrm{O}_{\mathrm{ads}}^{-} \\
& \mathrm{O}_{\mathrm{ads}}^{-}+\mathrm{V}_{0}{ }^{\prime} \rightleftharpoons \mathrm{O}_{0}^{x}+\mathrm{h}^{\circ} .
\end{aligned}
$$

Note that in all reactions $h^{\cdot}$ can be replaced by $\mathrm{e}^{\prime}$ on the other side of the reaction equation, depending on the type of electronic defect present.

It is clear that on most catalysts investigated neither reaction (1) nor reaction (5) can be rate-determining, since all orders in $\mathrm{CO}$ and $\mathrm{O}_{2}$ differ from 1. An exception may be TGZ0 heat-treated at $1423 \mathrm{~K}$, where the order in oxygen is nearly 1 and that in CO nearly 0 , suggesting in that case that reaction (5) is rate-determining.

\section{Calcined Catalysts}

In the system $\left(\mathrm{Tb}_{x} \mathrm{Gd}_{1-x}\right)_{2} \mathrm{Zr}_{2} \mathrm{O}_{7}$, increasing $x$ gives a decrease in the order of $\mathrm{CO}$, while that in $\mathrm{O}_{2}$ remains practically the same. This indicates a shift of the rate-determining step from reduction to reoxidation of the surface. This indicates increasing ease of reduction, which can be explained by the possibility of valence change of terbium:

$$
\mathrm{Tb}^{4+}+\mathrm{e}^{\prime} \rightleftharpoons \mathrm{Tb}^{3+}
$$

which is correlated with reaction (1) in the mechanism. Moreover, the presence of $\mathrm{Tb}$ increases the catalytic activity, probably for the same reason.

In the system $\left(\mathrm{Tb}_{x} \mathrm{Bi}_{1-x}\right)_{2} \mathrm{Zr}_{2} \mathrm{O}_{7}$ the order in $\mathrm{CO}$ increases and that in $\mathrm{O}_{2}$ decreases with increasing bismuth content, i.e. the rate-determining step shifts from reoxidation to reduction of the surface. This is in agreement with the literature, ${ }^{12,13}$ where it is shown that bismuth accelerates adsorption and/or surface diffusion of oxygen.

\section{Heat-treated Catalysts}

The heat treatment of the catalysts at 1423,1523 and $1623 \mathrm{~K}$ in principle leads to an increase in the degree of pyrochlore ordering, and in this way the catalytic behaviour 
may be influenced. As shown in table 4, the orders in $\mathrm{CO}$ and $\mathrm{O}_{2}$ are indeed strongly influenced in this way. The increase in pyrochlore ordering first leads to a decrease in the order in $\mathrm{CO}$ and an increase in that in $\mathrm{O}_{2}$, indicating increasing ease of reduction so that reoxidation becomes more rate-determining. This is probably caused by the formation of stable carboxylate complexes. ${ }^{2}$ As a consequence the occupation of a $\mathrm{CO}$ adsorption site hinders $\mathrm{O}_{2}$ chemisorption. The negative orders in $\mathrm{CO}$ indicate that the reactants adsorb either on the same sites or on closely neighbouring sites. With a further increase in ordering the order in $\mathrm{CO}$ increases again while that in $\mathrm{O}_{2}$ decreases. This may mean that the adsorption sites on the more completely ordered material are farther apart. One possibility is that in particular the boundaries between the ordered and unordered parts are the most active parts on the surface. This is similar to the proposal of Andersson ${ }^{14}$ that in the oxidation of aromatic hydrocarbons in particular the boundaries between phases are most active.

With increasing $\mathrm{Tb}$ content these differences become smaller and for $\mathrm{Tb}_{2} \mathrm{Zr}_{2} \mathrm{O}_{7}$ (TGZ100) they are reversed. In the latter compound only limited, very localized ordering (not related to the pyrochlore structure) is observed by transmission electron microscopy, ${ }^{15}$ which is probably the cause of the different behaviour.

As well as the effect on the orders there is also a strong influence on the catalytic activity. Here again partial ordering leads to an increase in activity, which decreases again with increased ordering.

When pyrochlore ordering is only present as microdomains distributed randomly in a fluorite matrix the activation energy for conduction is not changed. Only when the ordering becomes so great that microdomains come into contact does the activation energy start to decrease. For $\mathrm{Gd}_{2} \mathrm{Zr}_{2} \mathrm{O}_{7}$ (TGZ0) this results in an increase in total conduction. As suggested in the introduction, this might have a favourable influence on the catalytic activity. It is striking that the maximum in catalytic activity of TGZO is observed after a heat treatment which is insufficient for pyrochlore superstructure reflections to become visible in the X-ray diffractogram, so that ordering can only be present in the form of very small microdomains. A possible explanation for this effect is that the increased activity is due to an enhanced activity of the boundary between the ordered pyrochlore domains and the fluorite matrix, as also suggested above. If no ordered domains are present the activity is low. Correspondingly, when the domains become so large that they come into contact with each other the activity drops again. Because the conductivity is mainly determined by the bulk component (the fluorite matrix when only separated microdomains are present) this does not change much in the beginning of the ordering process, so that the expected correlation with conductivity is not observed. A problem in the description of the observations is the extremely large influence the reaction orders have on the reaction rates and on the reaction rate constants. For example, comparing TGZ0, 1423 with TGZ0, 1523 we have at $723 \mathrm{~K}$ :

$$
k_{\text {TGZ0, } 1423}=3.3 \times 10^{-1} \mathrm{~mol} \mathrm{~m}^{-2} \mathrm{~s}^{-1}\left(\mathrm{~mol} \mathrm{~cm}^{-3}\right)^{-0.85}
$$

which is much greater than

$$
k_{\mathrm{TGZ0}, 1523}=1.7 \times 10^{-3} \mathrm{~mol} \mathrm{~m}^{-2} \mathrm{~s}^{-1}\left(\mathrm{~mol} \mathrm{~cm}^{-3}\right)^{0.05}
$$

while for the reaction rates as given in table 4 we have:

$$
r_{\mathrm{TGZ0}, 1423} \ll r_{\mathrm{TGZ0}, 1523} \text { at } 723 \mathrm{~K} \text {. }
$$

This illustrates that, as indicated earlier, the description using the kinetic equation $r=k[\mathrm{CO}]^{n}\left[\mathrm{O}_{2}\right]^{m}$ makes it impossible to compare the $k$ and $k_{0}$ values directly, owing to the fact that these have changing dimensions depending on the values of $n$ and $m$.

As a better description might be obtained by using a kinetic equation based on the Mars-van Krevelen reduction-oxidation mechanism, as used for example by Agarwal et al. ${ }^{16}$ for the oxidation of methanol, several equations based on this were tested using 
Table 5. Kinetic parameters calculated for the oxidation-reduction mechanism

\begin{tabular}{|c|c|c|c|c|c|c|c|}
\hline \multicolumn{2}{|c|}{ catalyst } & $\begin{array}{c}E_{1} \\
/ \mathrm{kJ} \mathrm{mol}^{-1}\end{array}$ & $\begin{array}{c}E_{2} \\
/ \mathrm{kJ} \mathrm{mol}^{-1}\end{array}$ & $k_{10}$ & $k_{20}$ & $\begin{array}{c}10^{5} k_{1} \\
(723 \mathrm{~K})\end{array}$ & $\begin{array}{c}10^{5} k_{2} \\
(723 \mathrm{~K})\end{array}$ \\
\hline TGZ20 & 1073 & $87 \pm 3$ & $81 \pm 3$ & 22 & 3.8 & 1.1 & 1.1 \\
\hline TGZ10 & 1073 & $81 \pm 28$ & $96 \pm 21$ & 97 & 370 & 14 & 8.6 \\
\hline TGZ0 & 1423 & $228 \pm 40$ & $93 \pm 2$ & $4 \times 10^{14}$ & 94 & 1300 & 3.6 \\
\hline TGZ0 & 1523 & $174 \pm 84$ & $77 \pm 16$ & $6 \times 10^{12}$ & $8.8 \times 10^{3}$ & 160000 & 4800 \\
\hline
\end{tabular}

the multi-response regression computer program RKPES. ${ }^{17}$ As an example the results obtained for some catalysts using the equation:

$$
r=\frac{1}{\frac{1}{k_{1} p_{\mathrm{CO}}}+\frac{1}{k_{2} p_{\mathrm{O}_{2}}}}
$$

are given in table 5. Comparing these results with those based on the orders in $\mathrm{CO}$ and $\mathrm{O}_{2}$, and the rates given in tables 3 and 4 , it can be seen that they lead to the same conclusions. For example, comparing TGZ1000 1073 with TGZ20 1073 it is seen that both reduction and reoxidation of the catalyst are faster for the former. Furthermore, the reduction is less rate-determining than the oxidation. This is reflected by the increase in order for $\mathrm{CO}$ and the decrease in that for $\mathrm{O}_{2}$ (see table 4).

For TGZ0 1423 reoxidation of the catalyst has the largest influence $\left(k_{1} \gg k_{2}\right)$, which gives $r=k_{2}\left[\mathrm{O}_{2}\right]$, in agreement with the orders $-0.05 \pm 0.1$ and $0.9 \pm 0.1$ given in table 4. For TGZ0 1523 the deviations, e.g. in $E_{1}$ and $E_{2}$, are so large that no meaningful conclusions can be drawn in this case, probably owing to the negative order in $\mathrm{CO}$, which cannot be reproduced by an equation of the simple oxidation-reduction model. Of course it might be possible to apply more sophisticated models, ${ }^{16}$ but then more experimental data would be needed than are available. Because the qualitative conclusions remain the same it was decided to use the original kinetic equation.

\section{Conclusions}

In the compounds $\left(\mathrm{Tb}_{x} \mathrm{Gd}_{1-x}\right)_{2} \mathrm{Zr}_{2} \mathrm{O}_{7}$ the catalytic activity in $\mathrm{CO}$ oxidation increases with increasing terbium content. Simultaneously the order in $\mathrm{CO}$ decreases while that in $\mathrm{O}_{2}$ remains nearly unchanged. This can clearly be explained by the increasing concentration of charge carriers making reduction easier, while reoxidation is not much influenced.

Increasing bismuth content, in the compounds $\left(\mathrm{Tb}_{x} \mathrm{Bi}_{1-x}\right)_{2} \mathrm{Zr}_{2} \mathrm{O}_{7}$, causes the order in $\mathrm{CO}$ to increase while that in $\mathrm{O}_{2}$ decreases: bismuth facilitates oxygen uptake so that reoxidation becomes easier.

Heat treatment of the TGZ series of compounds was applied at temperatures of 1423, 1523 and $1623 \mathrm{~K}$ and has a great influence on the orders and the catalytic activity. At the lower temperatures of heat treatment and at the lower terbium contents the order in $\mathrm{CO}$ decreases: the reduction is facilitated. The negative orders in $\mathrm{CO}$ indicate that the reactants adsorb on the same or on closely neighbouring sites. With increasing ordering the order in $\mathrm{CO}$ increases. In the absence of terbium the order in $\mathrm{O}_{2}$ first increases and then decreases with increasing annealing temperature, while at TGZ100 with a very high terbium content the reverse is observed. At an intermediate terbium content the order in oxygen remains nearly constant.

The catalytic activity shows a maximum as a function of heat treatment and this is 
highest for TGZ0. TGZ40 and TGZ100 behave in this respect more like catalysts with a fluorite structure. This is clearly connected with the observation ${ }^{15}$ that pyrochlore formation is decreased with increasing terbium content.

The authors thank Dr G. M. H. van de Velde and Ir H. J. Fontein for their assistance with the computer calculations.

\section{References}

1 M. P. van Dijk, J. H. H. ter Maat, G. Roelofs, H. Bosch, G. M. H. van de Velde, P. J. Gellings and A. J. Burggraaf, Mater. Res. Bull., 1984, 19, 1149.

2 J. H. H. ter Maat, M. P. van Dijk, G. Roelofs, H. Bosch, G. M. H. van de Velde, P. J. Gellings and A. J. Burggraaf, Mater. Res. Bull., 1984, 19, 1271.

3 M. P. van Dijk, Thesis (Twente University of Technology, 1985).

4 M. P. van Dijk, K. J. de Vries and A. J. Burggraaf, Solid State Ionics, 1985, 16, 211.

5 M. P. van Dijk and A. J. Burggraaf, Solid State Ionics, 1985, 17, 159.

6 M. A. C. G. van de Graaf and A. J. Burggraaf, Sci. Tech. Zirconia 2, 1983, 12, 744.

7 Y. Yao, J. Catal., 1975, 39, 104.

8 P. Meriaudeau, M. Breysse and B. Claudel, J. Catal., 1974, 35, 184,

9 J. H. Lunsford and J. P. Jayne, J. Chem. Phys., 1966, 44, 1492.

10 W. S. Brey, R. B. Gammage and Y. P. Virmani, J. Phys. Chem., 1971, 75, 895.

11 K. H. Kim, S. H. Lee, Y. R. Kim and J. S. Choi, J. Catal., 1984, 88, 283.

12 M. J. Verkerk and A. J. Burggraaf, J. Electrochem. Soc., 1983, 130, 70.

13 B. C. H. Steele, J. A. Kilner, P. F. Dennis, A. E. McHale, M. van Hemert and A. J. Burggraaf, Solid State Ionics, 1986, 18/19, 1078.

14 A. Andersson, J. Catal., 1981, 69, 465; 1982, 76, 144.

15 M. P. van Dijk, F. C. Mijlhoff and A. J. Burggraaf, J. Solid State Chem., accepted for publication.

16 D. C. Agarwal, P. C. Nigam and R. D. Srivastava, J. Catal., 1978, 55, 1.

17 Y. Bard, Non-linear Parameter Estimation (Academic Press, New York, 1974), p. 61. 